\title{
Synthesis and Characterization of Indole-Containing Chromophores for Second-Order Nonlinear Optics
}

\author{
Wei Gong ${ }^{\dagger}$, Zhen $\mathrm{Li}^{\dagger} *$, Changgui $\mathrm{Lu}^{\ddagger}$, Jing Zhu${ }^{\ddagger}$, Sueyue $\mathrm{Li}^{\dagger}$, Qianqian Li ${ }^{\dagger}$, Junwei Yang ${ }^{\dagger}$, \\ Yiping Cui ${ }^{\ddagger *}$, Jingui Qin ${ }^{\dagger}$, \\ ${ }^{\dagger}$ Department of Chemistry, Wuhan University, Wuhan 400072, China \\ ${ }^{\ddagger}$ Advanced Photonics Center, Department of Electronic Engineering, Southeast University, Nanjing 210096, \\ China
}

\section{Supporting Information}

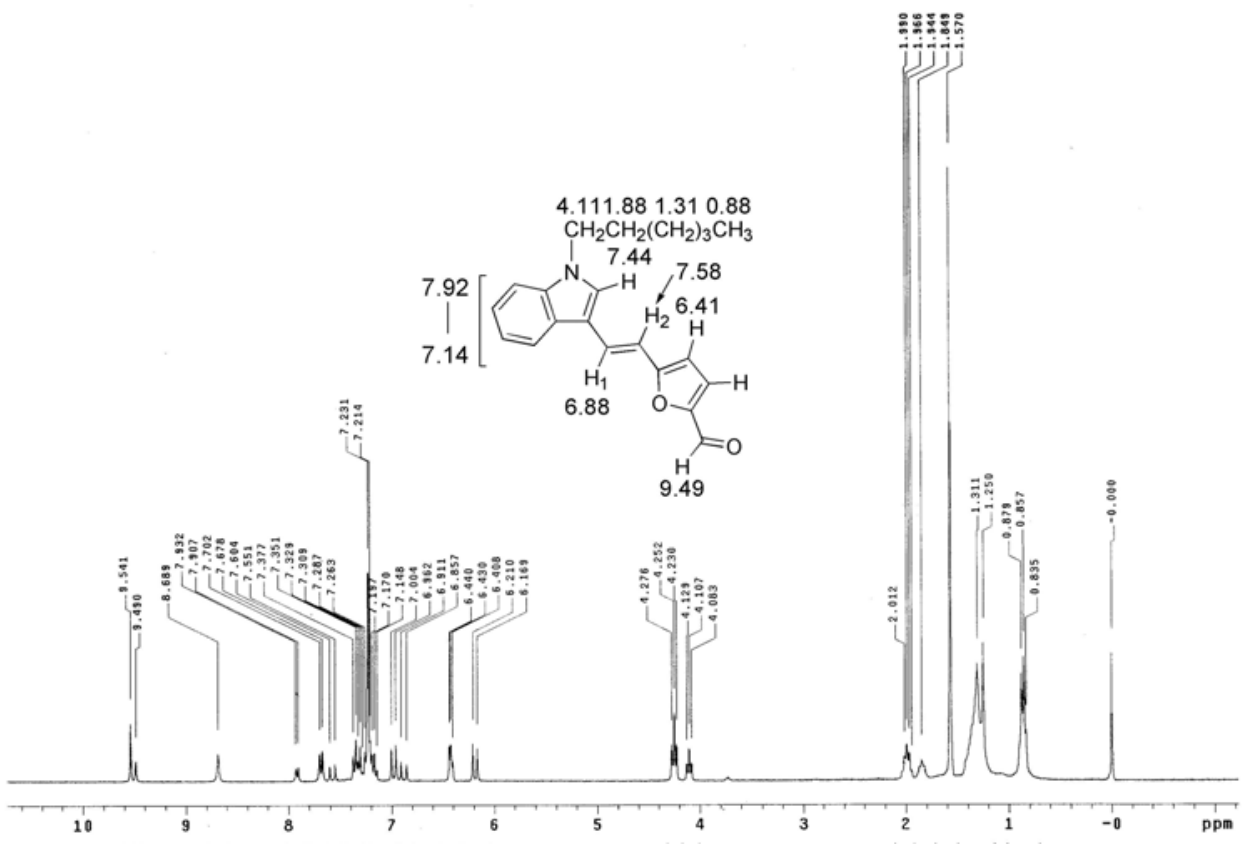

Figure S1. ${ }^{1} \mathrm{H}$ NMR spectrum of the chloroform- $d$ solution of $\mathbf{8}$. 


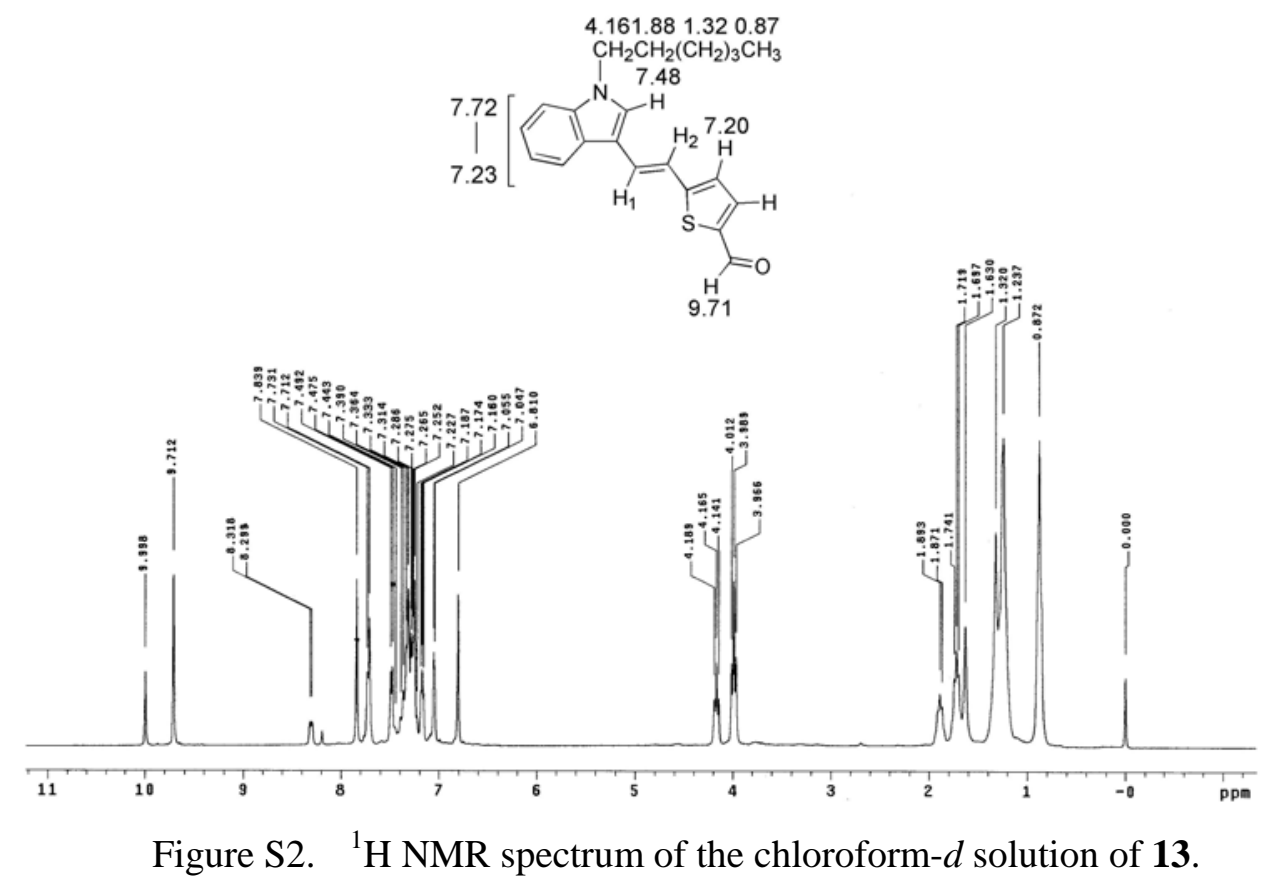




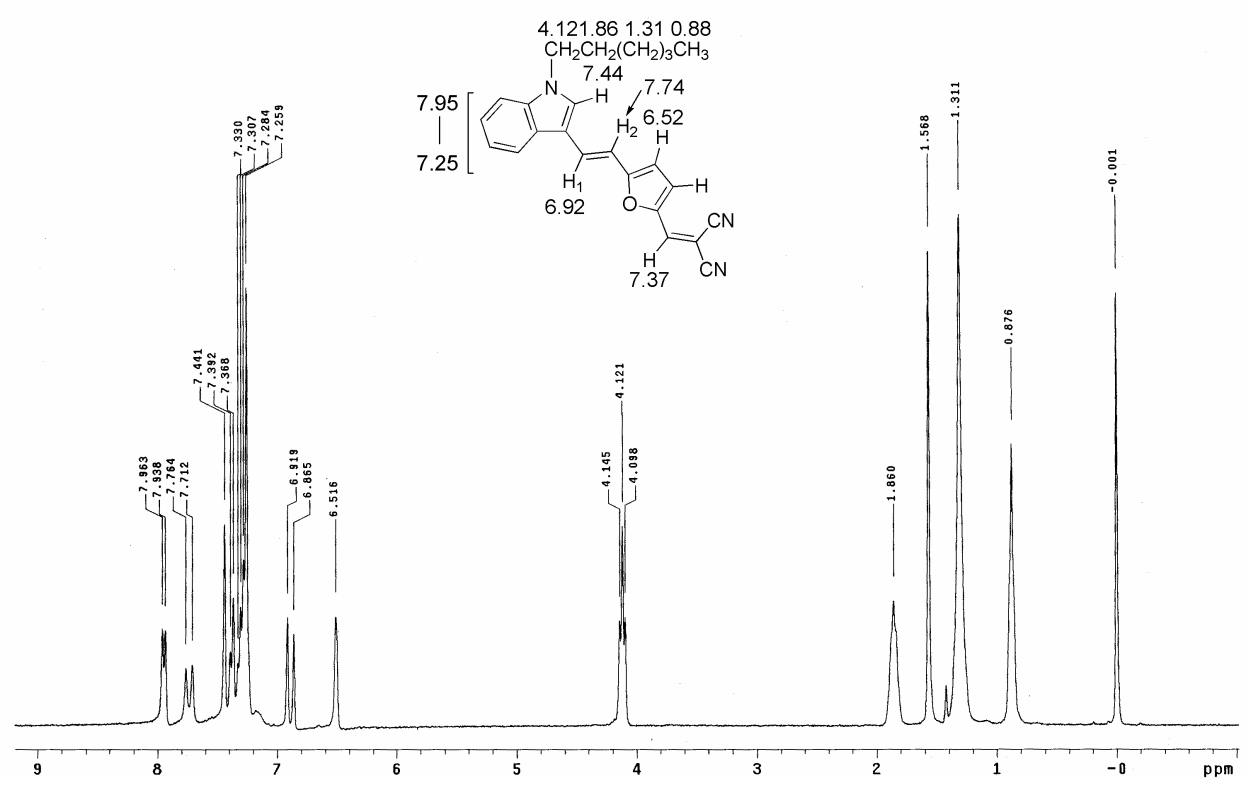

Figure S3. $\quad{ }^{1} \mathrm{H}$ NMR spectrum of the chloroform- $d$ solution of Ia. 


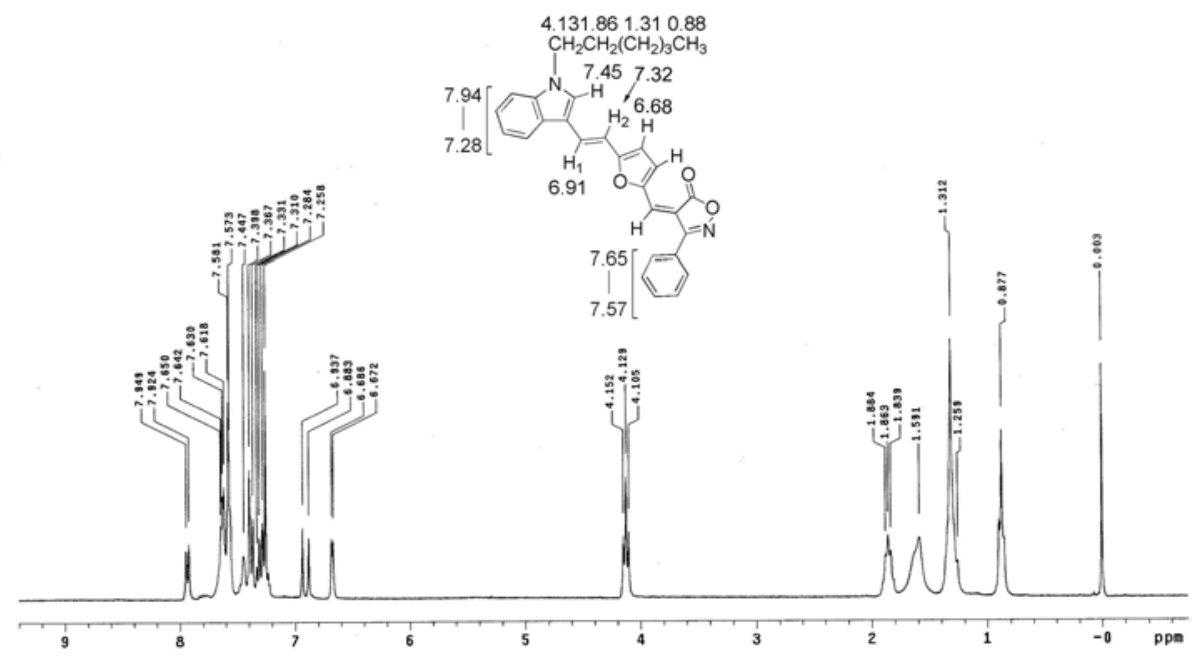

Figure S4. ${ }^{1} \mathrm{H}$ NMR spectrum of the chloroform- $d$ solution of Ib. 


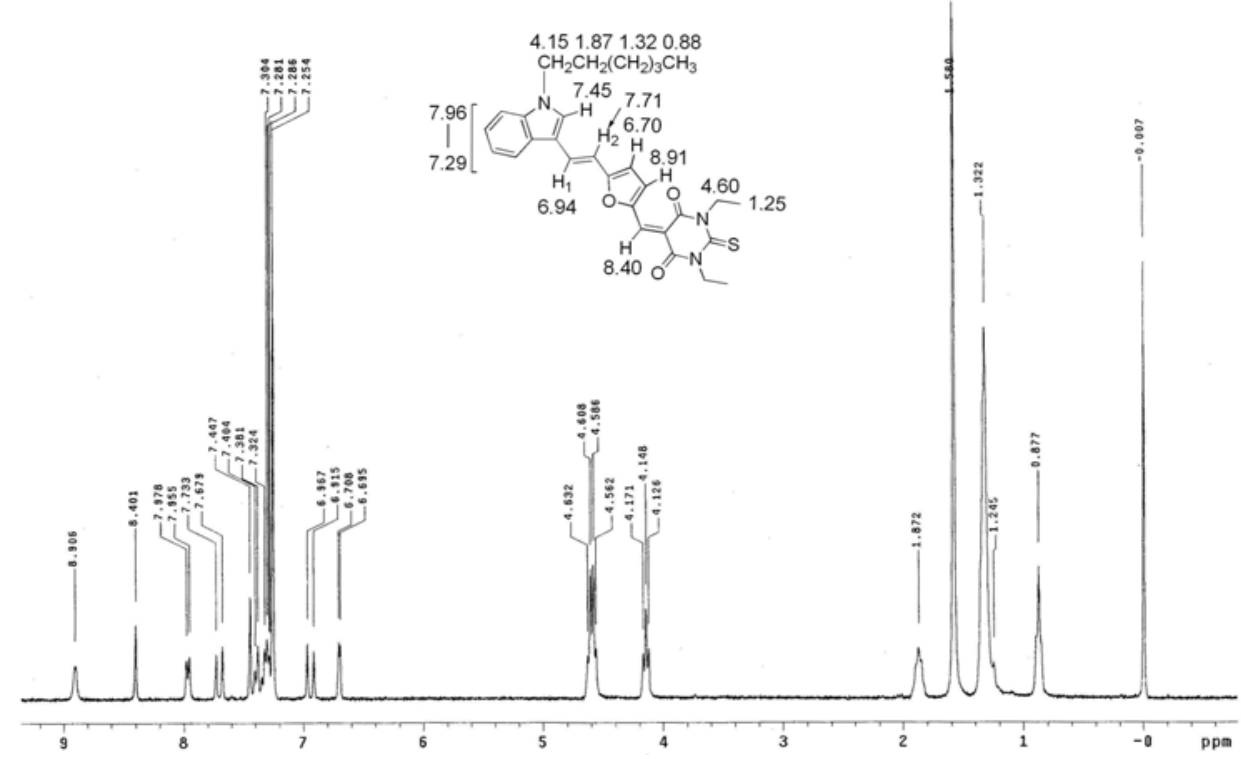

Figure S5. ${ }^{1} \mathrm{H}$ NMR spectrum of the chloroform- $d$ solution of Ic. 


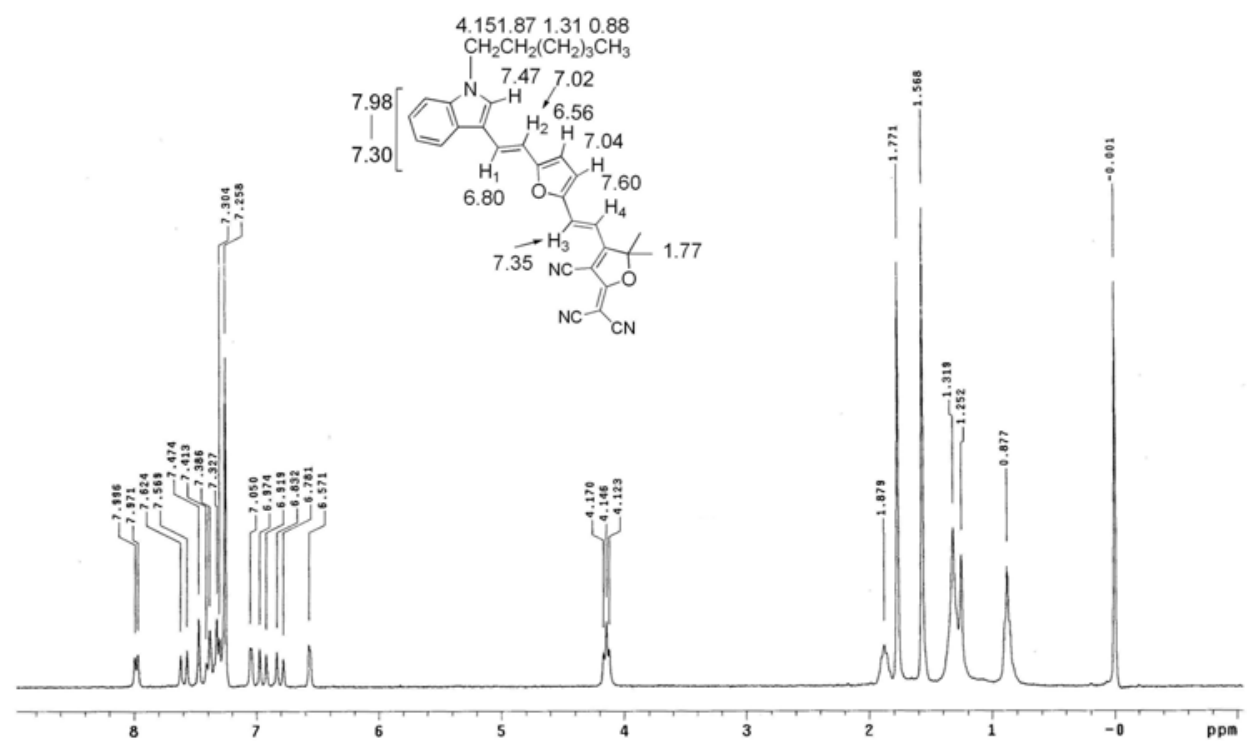

Figure S6. $\quad{ }^{1}$ H NMR spectrum of the chloroform- $d$ solution of Id. 


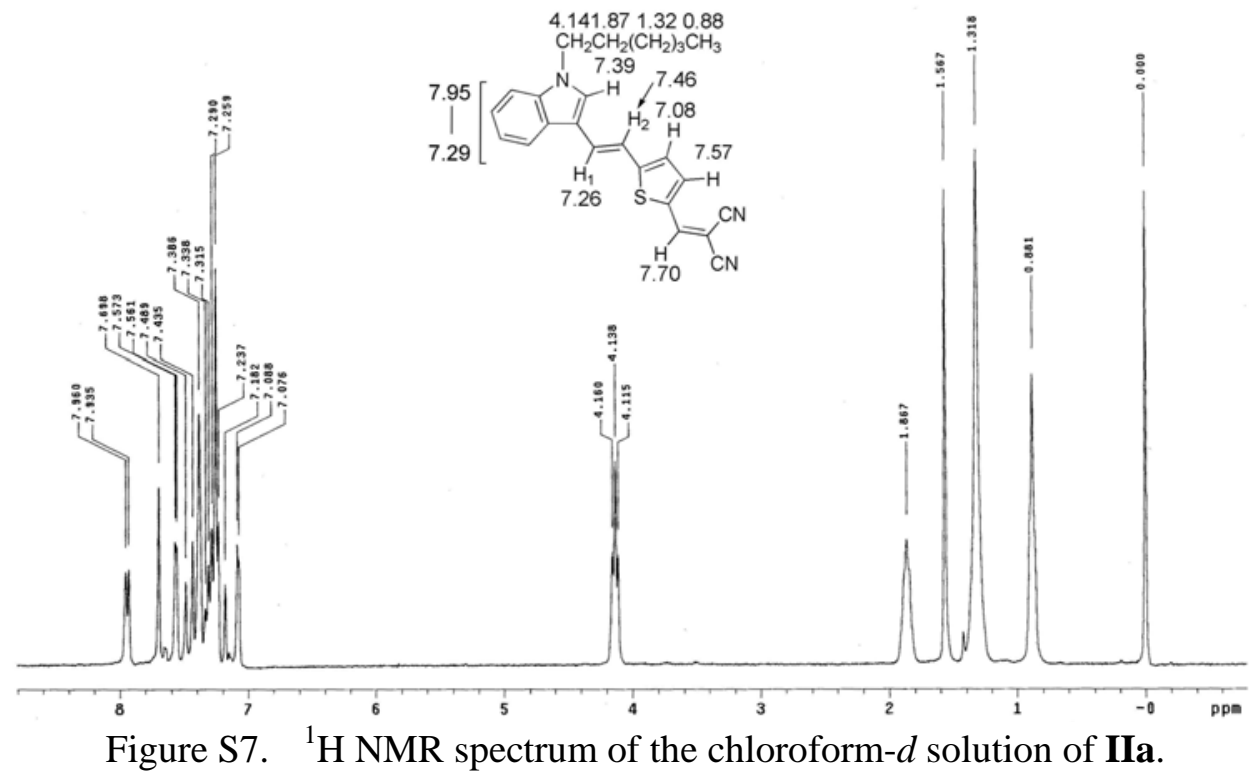




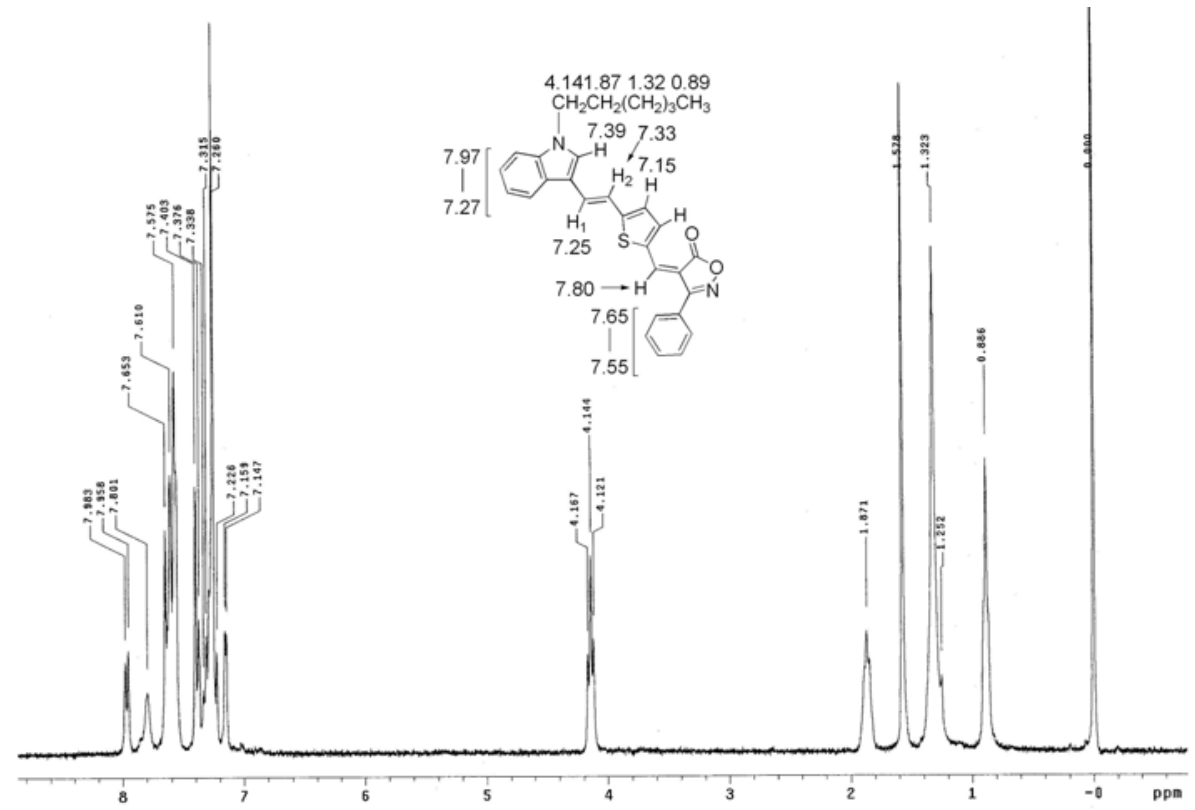

Figure S8. $\quad{ }^{1} \mathrm{H}$ NMR spectrum of the chloroform- $d$ solution of IIb. 


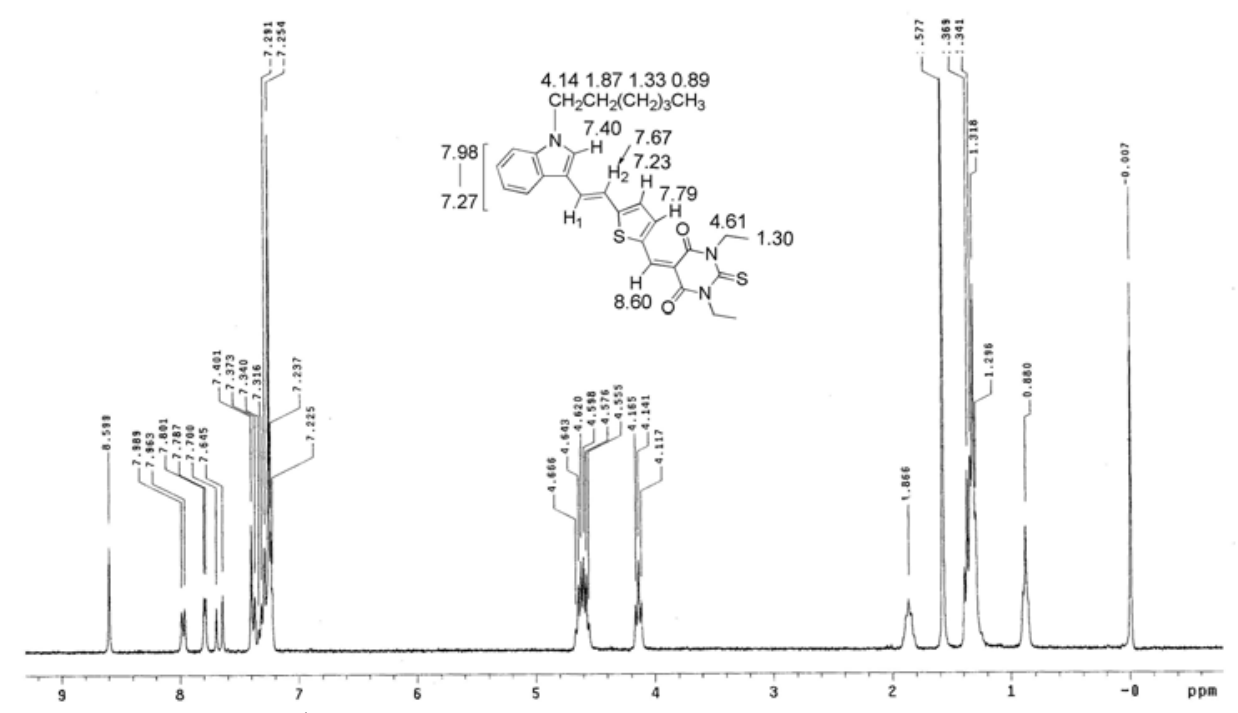

Figure S9. ${ }^{1} \mathrm{H}$ NMR spectrum of the chloroform- $d$ solution of IIc. 


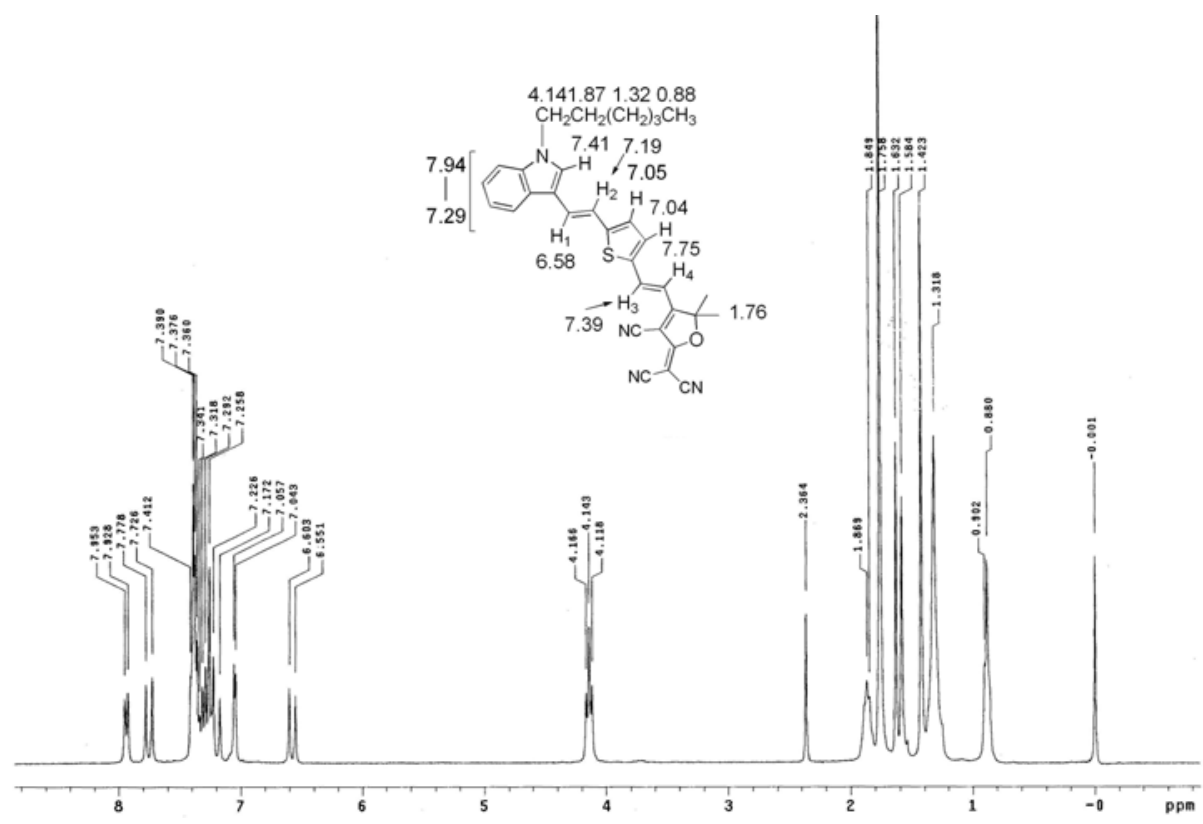

Figure S10. $\quad{ }^{1} \mathrm{H}$ NMR spectrum of the chloroform- $d$ solution of IId. 


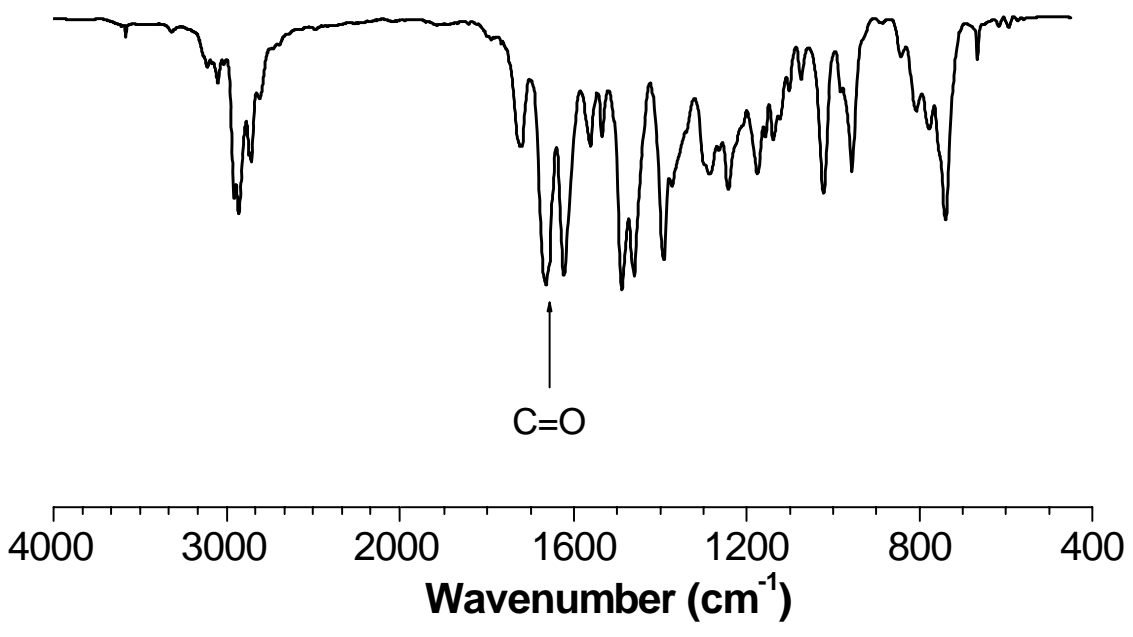

Figure S11. IR spectrum of 8. 


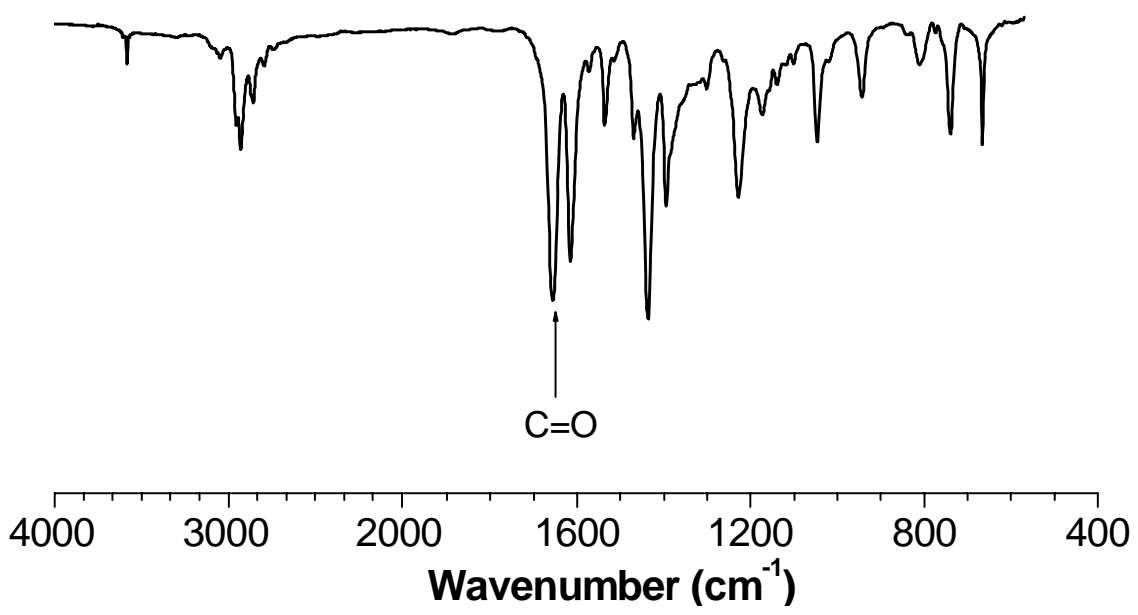

Figure S12. IR spectrum of $\mathbf{1 3}$. 


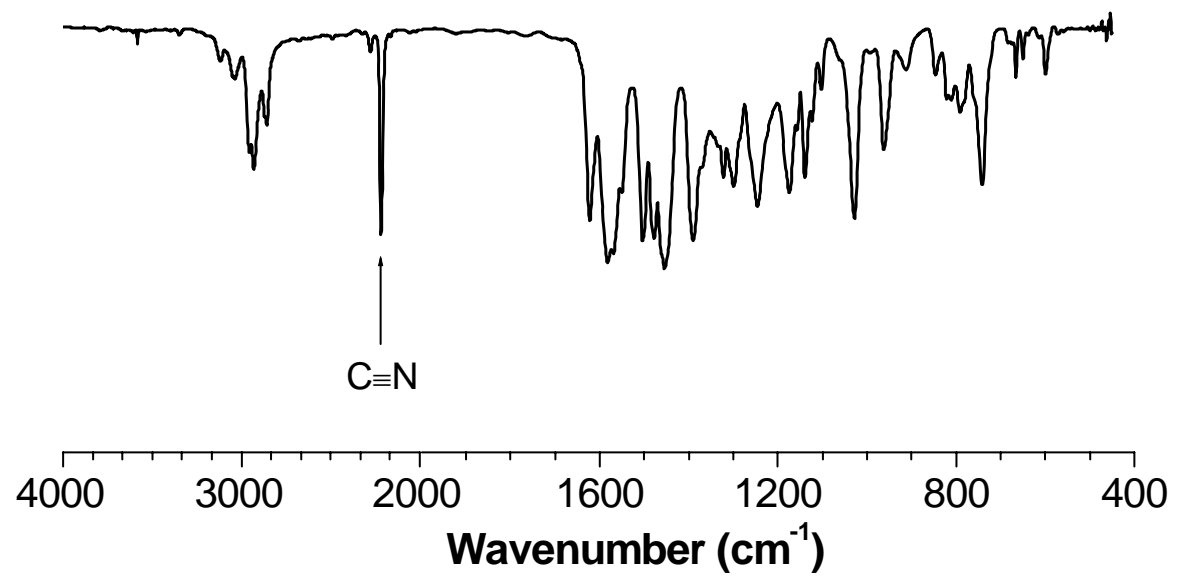

Figure S13. IR spectrum of Ia. 


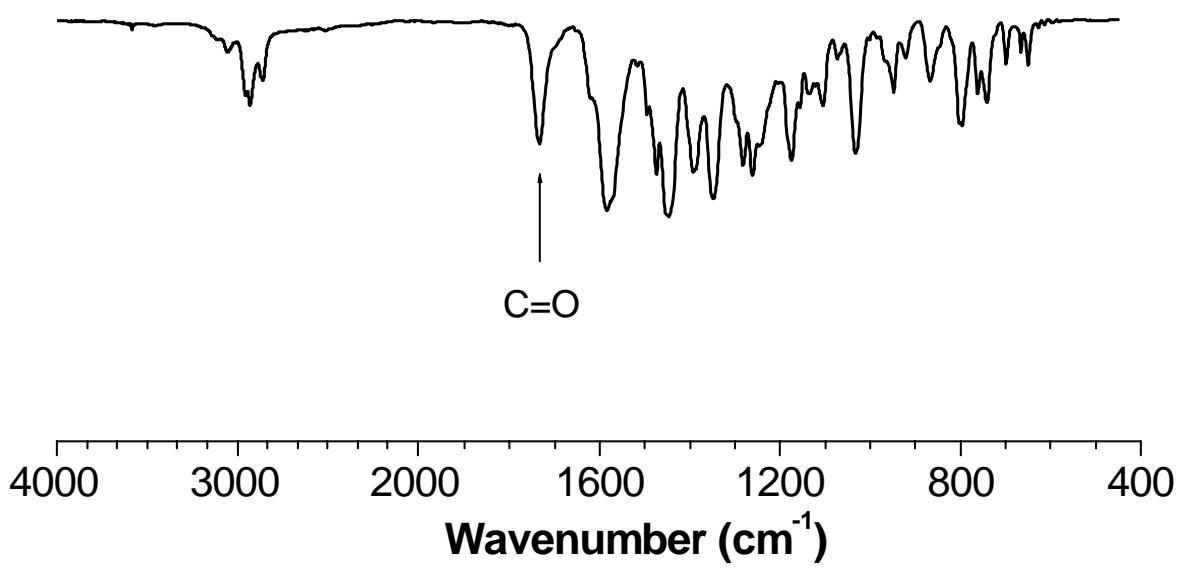

Figure S14. IR spectrum of Ib. 


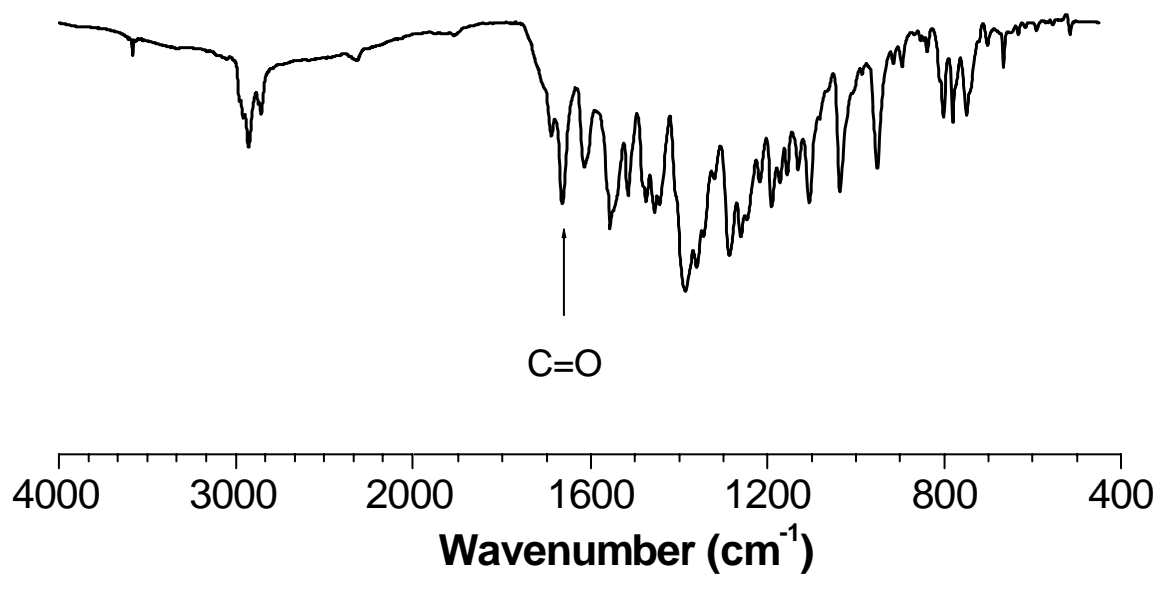

Figure S15. IR spectrum of Ic. 


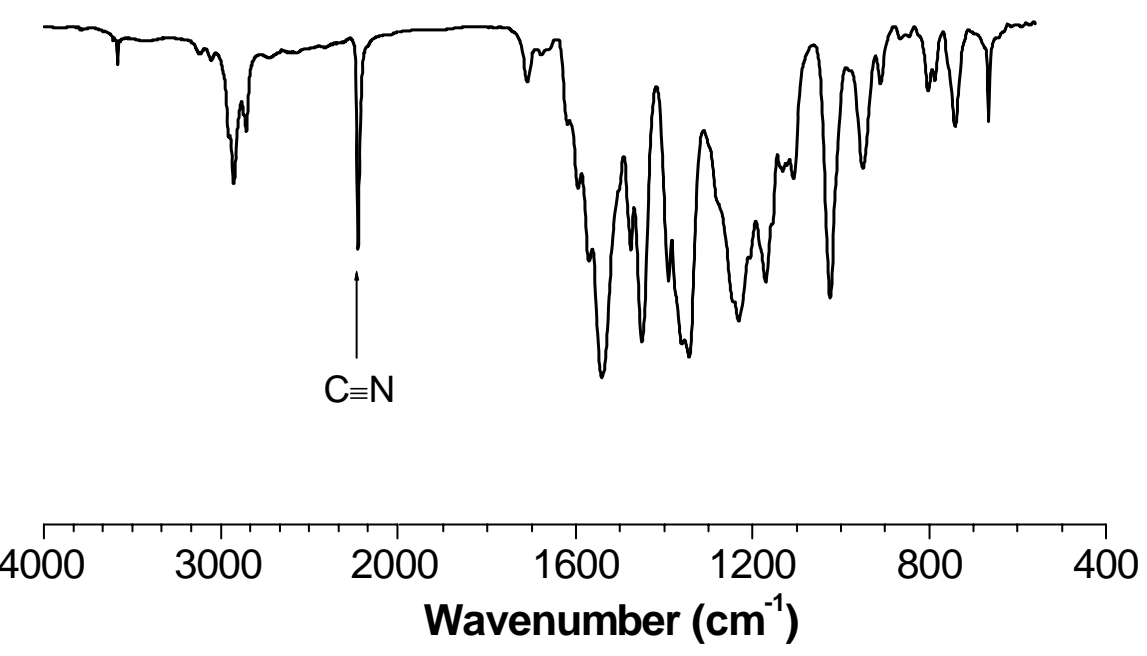

Figure S16. IR spectrum of Id. 


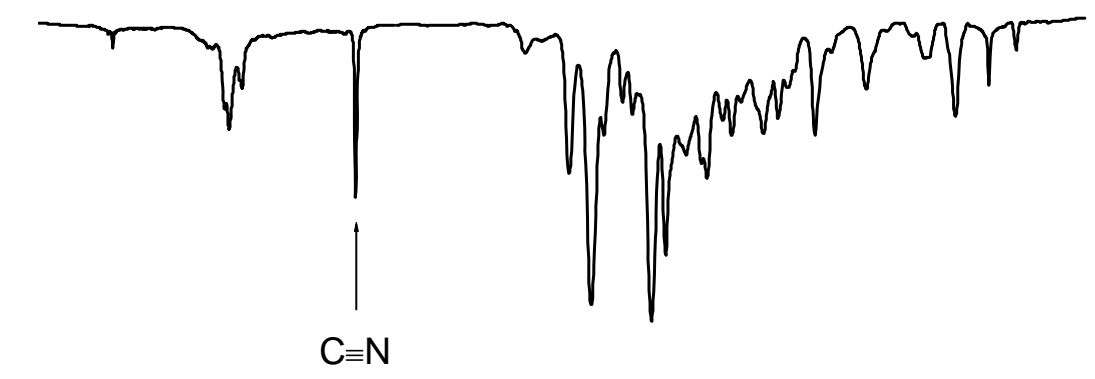

\begin{tabular}{|c|c|c|c|c|c|c|}
\hline 4000 & 3000 & 2000 & 1600 & 1200 & 800 & 400 \\
\hline
\end{tabular}

Figure S17. IR spectrum of IIa. 


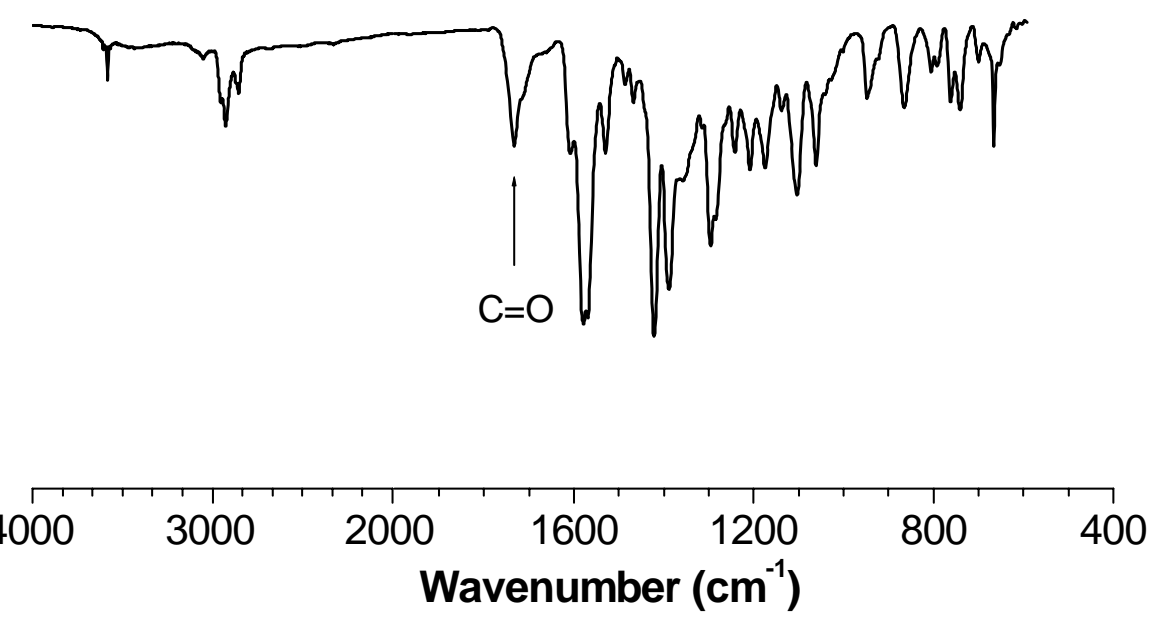

Figure S18. IR spectrum of IIb. 


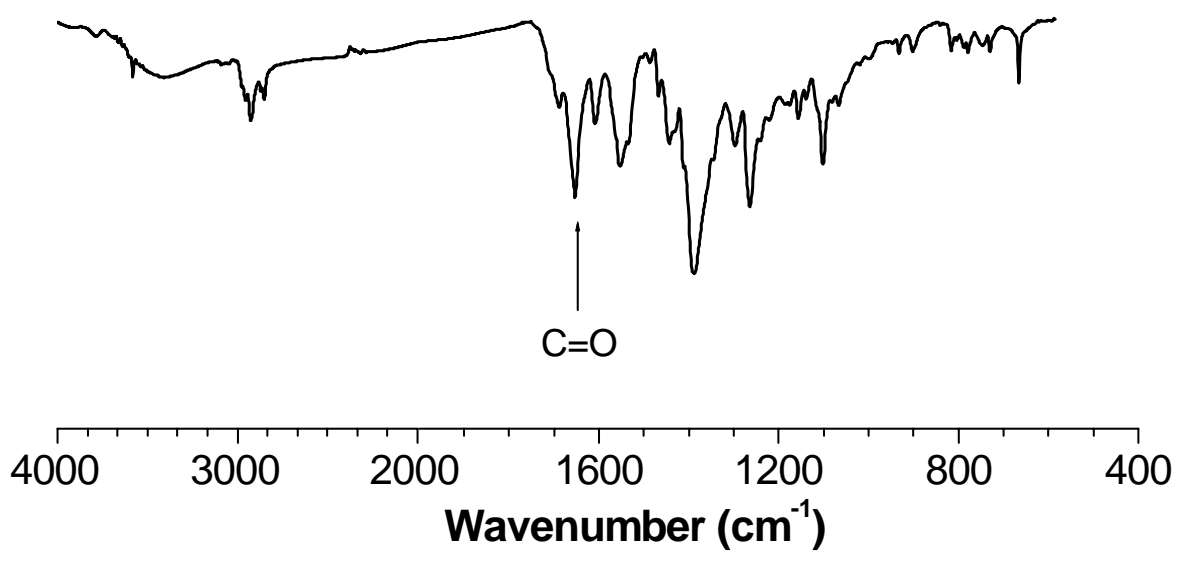

Figure S19. IR spectrum of IIc. 


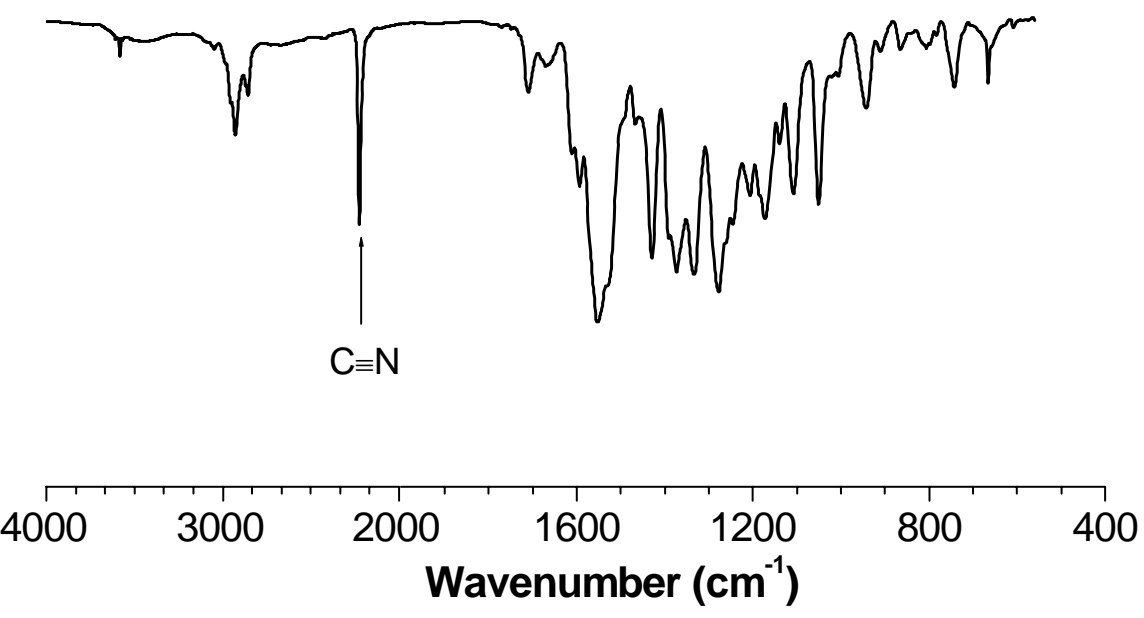

Figure S20. IR spectrum of IId. 